УДК 343.139

Даровских О.И.

ПРИНЦИП ДОБРОСОВЕСТНОСТИ

(НЕДОПУСТИМОСТЬ ЗЛОУПОТРЕБЛЕНИЯ

ПРАВОМ), КАК СРЕДСТВО ОБЕСПЕЧЕНИЯ

ЭФФЕКТИВНОЙ УГОЛОВНО-ПРОНЕССУАЛЬНОЙ ДЕЯтЕЛЬНОСТи

Darovskikh 0.I.

\title{
THE PRINCIPLE OF GOOD FAITH (INADMISSIBILITY OF ABUSE OF LAW) AS A MEANS OF ENSURING EFFECTIVE CRIMINAL PROCEDURAL ACTIVITY
}

\begin{abstract}
Статья посвящена такому принципу, обеспечивающему эффективную уголовно-процессуальную деятельность как добросовестность (недопустимость злоупотребления правом). В статье автор анализирует мнения ученых о возможности выделения специальных принципов и приходит к выводу о целесообразности выделения специальных принципов эффективной уголовно-процессуальной деятельности, выделяет требования, предъявляемые к специальным принципам, приводит аргументы, подтверждающие возможность отнесения добросовестности к принципам. Автор обосновывает необходимость дополнить главу 2 УПК РФ таким специфическим принципом как добросовестность (недопустимость злоупотребления правом), соблюдение которого гарантирует производство именно эффективной уголовно-процессуальной деятельности.
\end{abstract}

Ключевые слова: эффективная деятельность, уголовно-процессуальная деятельность, принцип, добросовестность, злоупотребление, права.

The article is devoted to such a principle that ensures effective criminal procedural activity as conscientiousness (inadmissibility of abuse of law). In the article, the author analyzes the opinions of scientists about the possibility of identifying special principles and comes to the conclusion that it is advisable to single out special principles of effective criminal procedural activity, highlights the requirements for special principles, gives arguments confirming the possibility of attributing conscientiousness to principles. The author substantiates the need to supplement Chapter 2 of the Code of Criminal Procedure of the Russian Federation with such a specific principle as good faith (inadmissibility of abuse of law), the observance of which guarantees the production of an effective criminal procedural activity.

Keywords: effective activity, criminal procedural activity, principle, good faith, abuse, rights.

Принципы уголовно-процессуальной деятельности, указанные в главе 2 уголовно-процессуального закона Российской Федерации как основные, исходные, руководящие положения по ее осуществлению, безусловно распространяются на любую деятельность, в том числе и на эффективную. Однако сама по себе эффективная деятельность требует несколько иного подхода и дополнительных, можно сказать особых средств, обеспе- чивающих ее успешное осуществление, нежели применение только тех общих правил, которые указаны в действующем законе.

Подход к выявлению и констатации системы принципов, регулирующих отдельные стадии процесса, либо деятельность отдельных должностных лиц, не нов. Об этом писали и считали это разумным М.C. Строгович [16, с. 56, 367.] который выделял принцип предварительного след- 
ствия, А.П. Гуляев [6, с. 32], утверждавший о существовании принципов деятельности следователя, В.Л. Будников высказывался за наличие системы процессуальных принципов предварительного следствия [3, с. 70-72]. М.Л. Якуб выделял принципы судебного разбирательства [20, с. 45, 139], Е.Р. Ергашев в 2008 году защитил докторскую диссертацию на тему «Принципы прокурорско-надзорного права и его институтов» [8]. Разделяли принципы уголовного процесса, на принципы, характеризующие досудебное и судебное производство Ю.К. Якимович и Т.Д. Пан [19, с. 42]. В.П. Кашепов указывал, что «...содержание осуществляемого судами в порядке уголовного судопроизводства правосудия и принятых судами решений должно характеризоваться следующими качествами: а) законностью, определяемой как соответствие принятых решений и порядка рассмотрения дел закону; б) обоснованностью, т.е. подтверждением принятых решений убедительными и достаточными доказательствами; в) объективностью, т.е. непредвзятостью, беспристрастностью судебного исследования всех обстоятельств дела; г) полнотой как законченностью, исчерпанностью изучения всех доступных суду доказательств; д) справедливостью решений суда как соответствующих нравственным представлениям современного общества; е) своевременностью и юридической точностью принимаемых решений, незамедлительностью и общеобязательностью их исполнения» [10, с. 101112].

Полагаем, что данный подход к выделению специфических принципов определенной деятельности не просто имеет право на существование, но и целесообразен, поскольку позволяет более глубоко и последовательно выделять наиболее важные, ключевые моменты эффективной уголовно-процессуальной деятельности.

Выделение специальных принципов эффективной деятельности в отраслевом законодательстве, предопределено рядом объективных моментов и в первую очередь тем, что они отражают специфику именно эффективной уголовно-процессуальной деятельности, во-вторых, их исследование дополняет и расширяет имеющиеся знания о принципах уголовного процесса, позволяют выработать конкретные рекомендации по совершенствованию действующего законодательства, соответствующие современным требованиям правовой политики государства.
Специальные принципы, обеспечивающие эффективное уголовное судопроизводство, априори должны:

- выражать сущность, природу, характерные черты, содержание именно эффективной уголовно-процессуальной деятельности;

- носить не просто ориентирующий, а руководящий характер. Ими надо руководствоваться при применении иных норм для их понимания, при коллизии и при решении вопросов, не урегулированных законом;

- они должны обеспечивать достижение цели и решение задач, которые ставит перед собой конкретное должностное лицо при осуществлении уголовно-процессуальной деятельности и эти цели, и задачи изначально должны быть ориентированы на достижение эффективной деятельности;

- принципы, обеспечивающие эффективную уголовно-процессуальную деятельность, должны быть сформулированы в законе;

- они должны носят объективный характер, взаимодействовать с иными принципами.

Принципы могут формулироваться законодателем как отдельные нормы, либо существовать как «скрытые», спрятанные в конкретных нормах общие нормативные положения [2, с. 103-104], поэтому некоторые ученые, а мы придерживаемся именно данной точки зрения, полагают, что количество принципов уголовного судопроизводства намного больше того количества, которое указал законодатель в главе 2 УПК РФ. Такую точку зрения высказывали А.С. Александров [1, с. 162178], А.А. Тарасов [17, с. 71], А.В. Смирнов и К.Б. Калиновский [15, с. 471-472] и другие процессуалисты. Поэтому система принципов уголовного судопроизводства не может быть закрытой, ограниченной. С развитием общественных отношений, их изменением и появлением новых, требующих правового регулирования вполне логично, что появляются и новые требования, основополагающие руководящие положения, выражающие сущность этих новых явлений, обеспечивающие как соблюдение процессуальной формы, так и решения, поставленных в настоящий период времени, задач. Следует отметить, что данная тенденция соответствует позиции законодателя, который в 2010 году ввел в систему принципов такой принцип как «Разумный срок уголовного судопроизводства», а в 2013 году принцип «Независимость судей» [7, с. 43, $45,46]$. 
В связи с тем, что изменились требования общества к уголовно-процессуальной деятельности не только к её результатам, но и к процедуре осуществления, целесообразно разработать модель тех основных исходных идей, основных правил в которых бы воплощалась сущность именно эффективной деятельности в рамках урегулирования уголовно-процессуальных отношений. Анализ критериев признания деятельности эффективной позволил разработать и обосновать дополнительную систему специфических принципов, соблюдение которых гарантирует производство именно эффективной уголовно-процессуальной деятельности.

К их числу, по нашему мнению, следует отнести: такую правовую категорию как добросовестность (недопустимость злоупотребления правом).

Указанное правовое положение вправе претендовать на роль принципа поскольку по своей сути представляет собой ту мировоззренческую идею, которая способна таким образом детерминировать уголовно-процессуальную деятельность, чтобы она отвечала всем запросам общества на определенном этапе его развития. Данное правовое положение свободным образом проявляется в нормах уголовно-процессуального закона, может реализоваться в любой стадии процесса, ориентирует правоприменителей на то, как должна осуществляться процессуальная деятельность.

Конституция Российской Федерации гласит, что «Осуществление прав и свобод человека и гражданина не должно нарушать права и свободы других лиц» (ч. 3 ст. 17). Данное положение позволяет сделать обоснованный вывод о том, что реализация субъективных прав и законных интересов, в том числе и в уголовном судопроизводстве имеет пределы и ограничена соблюдением прав и законных интересов других лиц, участвующих в уголовном процессе. По своей сути, данное конституционное положение представляет собой требование, предъявляемое к участвующим в процессе лицам, вести себя определенным образом, а именно, не злоупотреблять предоставленными им конституционными правами. Такой точки зрения придерживались многие ученые [18, с. 52; 13, с. 199; 11, с. 124]. Данное положение, в определенных случаях конкретизировано указанием в уголовнопроцессуальном законе на обязанности участвующего в уголовном судопроизводстве лица, в других случаях, только презюмирует добросовестное поведение участника уголовно-процессуальных правоотношений. Выход за пределы данного требования чреват признанием совершенных действий незаконными, наложением определенных установленных законом санкций, отказом в защите прав и т.д. Например, в уголовно-процессуальном законе презюмируется добросовестность со стороны следователя, который принял дело к своему производству и ведет расследование, в отношении фиксации его результатов, независимо от того, что данная процессуальная фигура отнесена к стороне обвинения и на практике встречается достаточно примеров, когда следователи злоупотребляли своими правами. Например, в ходе судебного заседания в суде субъекта Российской Федерации по обвинению К., С., В. и Д было установлено, что явившуюся в суд свидетельницу, ранее следователь не допрашивал, хотя ее показания в материалах уголовного дела имелись. Вызванный и допрошенный по этому факту следователь пояснил, что сроки расследования заканчивались, направлять отдельное поручение по месту жительства свидетельницы, в город Санкт - Петербург не было времени, поэтому он и написал показания, какие посчитал нужными, сам [21]. Данная ситуация потребовала от суда соответствующего реагирования и в адрес руководителя следственного органа было направлено частное определение.

Закрепление в Конституции Российской Федерации положения о недопустимости злоупотребления правами позволило говорить об отнесении данной правовой категории к принципам права. О том, что принцип недопустимости злоупотребления правом является общеправовым принципом, указывает Конституционный Суд Российской Федерации в ряде своих Постановлении и Определений. Например, в Постановлении от 12 апреля 2002 года № 9-П «По делу о проверке конституционности положений статей 13-14 Федерального Закона «Об общих принципах организации законодательных (представительных) и исполнительных органах государственной власти субъектов РФ в связи с жалобой А.П. Быкова, а также запросами Верховного Суда Российской Федерации и Законодательного Собрания Красноярского края» указано, что «...При этом в силу общеправового принципа недопустимости злоупотребления правом неприкосновенность не может служить основанием освобождения от ответственности за публичные оскорбления, клевету и другие подобные им несовместимые с предна-

\section{9}

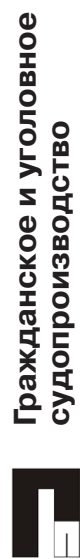


значением данного института и со статусом депутата правонарушающие деяния, предусматриваемые федеральным закоHOM».

Верховный Суд Российской Федерации также считает, что запрет злоупотреблять правами представляет собой общеправовой принцип, об этом говорится, например, в Постановлении Верховного Суда Российской Федерации № 2 от 17 марта 2004 года «О применении судами Российской Федерации Трудового кодекса Российской Федерации». Утверждение, о недопустимости злоупотребления правом можно встретить и в решениях судов различных уровней [22].

Аналогичного мнения придерживаются и некоторые ученые [5, с. 58; 12 , с. 54; 14 , с. 8, 127]. Нам представляется необходимым проанализировать доводы в пользу данной точки зрения.

Исходя из смысла термина «принцип», означающего начало, основу, правовые принципы определяются как основополагающие идеи, закрепленные в законе. Они приобретают значение императивных требований, конкретных правил и обязывают правоприменителя к определенному поведению или устанавливают определенные запреты [9, с. 92]. Принципы права играют важную роль в процессе правового регулирования, поскольку определяют основные направления юридического воздействия. Они объективны по характеру и зависят от субъективной воли законодателя, обусловлены объективными законами общественной жизни [4, c. 117].

В зависимости от сферы распространения общепринято различать общеправовые принципы, межотраслевые и отраслевые. Общеправовые принципы представляют собой основу системы права, всех ее отраслей и институтов. Они отражают сущность всей правовой системы и имеют двойственное проявление, с одной стороны они являются непосредственно действующими, с другой, отражаются в межотраслевых и отраслевых принципах. На этих принципах базируется правовое регулирование всех правоотношений в обществе.

Как правило, многие из данных принципов закреплены в Конституции Российской Федерации.

Нам представляется, что такой правовой категории как недопустимость злоупотребления правами, присущи все признаки и свойства принципа, реализующегося как на общеправовом уровне, так и на отраслевом: высокая степень общности; действие на протяжении всего уго- ловного судопроизводства; согласованность и связь с другими принципами; нормативно-правовой характер; выражение господствующих в государстве политических и правовых идей, касающихся способов осуществления судопроизводства по уголовным делам; возможность применения в качестве критерия законности действий и решений. Этот вывод подтверждается следующими аргументами.

Во-первых, недопустимость злоупотребления процессуальными правами в рамках уголовного судопроизводства, представляет собой общее положение. Невозможно в законодательстве конкретизировать все запреты, установить все пределы осуществления субъективных прав. Любые попытки сделать это не исчерпают всех возможных проявлений незаконных средств и способов осуществления своих прав. В определенных случаях данное принципиальное положение конкретизируется в рамках прав определенного участника процесса, применимо к конкретным стадиям, либо конкретным процессуальным действиям, но при этом существует как самостоятельная юридическая категория, обоснованность и объективный характер которой не вызывает сомнений. Она существует вне зависимости от конкретных лиц, участников процесса, от их правового и социального статуса, обстоятельств уголовного дела и каких-то иных отправных моментов.

Во-вторых, недопустимость злоупотребления процессуальными правами, т.е. добросовестное использование предоставленных прав, обеспечивает реализацию государственной правовой политики, определенных целей и задач. В уголовно-процессуальной деятельности обеспечивается достижение назначения уголовного судопроизводства, которое определено как защита прав и законных интересов лиц и организаций, потерпевших от преступлений; защита личности от незаконного и необоснованного обвинения, осуждения, ограничения ее прав и свобод. Желание защитить и потерпевших, и обвиняемых, обладающих противоречивыми интересами, априори предполагает необходимость выработки механизма, обеспечивающего достижение этой цели и в первую очередь содержащего как определенные гарантии возможности реализации прав указанными лицами, так и определенные ограничения в реализации прав, путем определения их пределов. Тем самым проявляется демократическая и гуманистическая составляющая данного принципа, которая обеспечивает проведение уголовно-процессу- 
альной деятельности в соответствии с ее социальным назначением.

В-третьих, недопустимость злоупотребления процессуальными правами, являясь принципом уголовного процесса, взаимодействует с иными принципами, проявляясь в них и обеспечивая их реализацию. Например, добросовестное отношение к реализации своих прав и обязанностей, взаимосвязано с принципом законности, поскольку любое злоупотребление правами нарушает указанный принцип. Добросовестное отношение должностных лиц в уголовном процессе обеспечивает возможность защиты прав и законных интересов любых участников процесса как обвиняемых, так и потерпевших, позволяет правильно оценивать все доказательства, собранные по делу, а участникам процесса эффективно реализовать свое право на обжалование процессуальных действий и решений.

Однако возникает проблема, которая требует своего решения, и которая по своей сути представляет следующий при- знак принципа его обязательное нормативное закрепление. Закрепление категории «недопустимость злоупотребления правом» только в тексте Конституции Российской Федерации и в форме, которая требует толкования, на наш взгляд является недостаточным для полноценной реализации данного принципа.

Мы согласны с устоявшимся в науке мнением, что принцип должен быть закреплен в законе, поэтому данное упущение законодателя требует, на наш взгляд, устранения. В будущем необходимо четкое закрепление данного принципа в текст Основного закона страны, добавив в ст. 17 часть четвертую следующего содержания «Злоупотребление правами не допускается», а в главу вторую уголовно-процессуального закона статью 7 «Добросовестность в уголовном судопроизводстве» следующего содержания: «1. Участники уголовного судопроизводства обязаны добросовестно использовать предоставленные им права. 2. Злоупотребление правами не допускается»» [7, с. 52-60].

\section{Литература}

1. Александров А.С. Принципы уголовного судопроизводства // Правоведение. - 2003. - № 5. - C. 162-178.

2. Алексеев С.С. Проблемы теории права: курс лекции в 2-х томах. Т.1. - Свердловск, 1972. - С. 103-104.

3. Будников В.Л. О понятии, значении и системе процессуальных принципов предварительного следствия // Общество, право, власть: межвузовский сборник научных трудов Современные проблемы правовой реформы. - Волгоград, 1997. - 4.1. - С. 70-72.

4. Власенко Н.А. Теория государства и права. Научно-практическое пособие для самостоятельной подготовки студентов всех форм обучения. - М.: ИД «Юриспруденция», 2009. - 424 с.

5. Гаджиев Г.А. Конституционные принципы добросовестности и недопустимости злоупотребления субъективными правами // Государство и право. - 2002. - № 7. - С. 54-62.

6. Гуляев А.П. Следователь в уголовном процессе. - М., 1981. - 192 с.

7. Даровских О.И. Актуальные проблемы уголовного процесса: учебное пособие. - Челябинск: Издательский центр ЮУрГУ, 2019. - Ч.1. - 199 с.

8. Ергашев Е.Р. Принципы прокурорско-надзорного права и его институтов: дис ... докт. юрид. наук. - Екатеринбург, 2008. // Режим доступа: https://www. dissercat.com/content/printsipy-prokurorskogo-nadzorno-okhranitelnogo-pravai-ego-institutov-0

9. Зажицкий В.И. Правовые принципы в законодательстве Российской Федерации // Государство и право. - 1996. - № 11. - С. 92-98.

10. Кашепов В.П. Гуманизация уголовного судопроизводства как принцип регулирования российского правосудия // Журнал российского права. 2015. - № 12. - С. 101-112. // Режим доступа https://cyberleninka.ru/article/n/ gumanizatsiya-ugolovnogo-sudoproizvodstva-kak-printsip-regulirovaniyarossiyskogo-pravosudiya

11. Комментарий к Конституции РФ / под ред. Б.Н. Топорнина, Ю.М. Батурина, Р.Г. Орехова. - М., 1994. -623 с.

12. Малиновский А.А. Злоупотребление правом. - М., 2002. - 128 с.

13. Малиновский А.А. Злоупотребление субъективным правом как юридический феномен: дис. ... докт. юрид. наук. - М., 2003. - 404 с.

14. Мурадьян Э.М. Судебное право. - М., 2003. - 128 с.

15. Смирнов А.В., Калиновский К.Б. Уголовный процесс. - СПб., 2004. - 704 с.

16. Строгович М.С. Курс советского уголовного процесса. - М., 1970. - Т. 2. -616 c.

17. Тарасов А.А. Развитие системы принципов уголовного процесса в новом УПК России // Уголовно-процессуальный кодекс Российской Федерации: год правоприменения и преподавания. - М., 2004. - С. 71

121

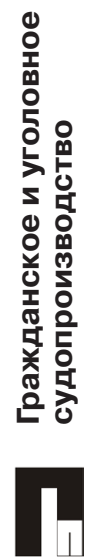


18. Юдин А.В. Злоупотребление процессуальными правами в гражданском судопроизводстве. - СПб.: Издательский дом С.-Петерб. гос. ун-та, издательство юридического факультета, 2005. - 360 с

19. Якимович Ю.К., Пан Т.Д. Судебное производство по УПК Российской Федерации. - СПб, 2005. - 264 с.

20. Якуб М.Л. Демократические основы советского уголовно-процессуального права. - М., 1960. - С. 135-138.

21. Архив Кустанайского областного суда. Уголовное дело № 3998-19-00-1/73. 22. Определение Московского областного суда от 31 января 2012 года № 33$2405 / 12$.

\section{References}

1. Aleksandrov A.S. Printsipy ugolovnogo sudoproizvodstva // Pravovedeniye. 2003. - № 5. - S. 162-178.

2. Alekseyev S.S. Problemy teorii prava: kurs lektsii v 2-kh tomakh. T.1. - Sverdlovsk, 1972. - S. 103-104.

3. Budnikov V.L. O ponyatii, znachenii i sisteme protsessual'nykh printsipov predvaritel'nogo sledstviya // Obshchestvo, pravo, vlast': mezhvuzovskiy sbornik nauchnykh trudov Sovremennyye problemy pravovoy reformy. - Volgograd, 1997. - CH.1. - S. 70-72.

4. Vlasenko N.A. Teoriya gosudarstva i prava. Nauchno-prakticheskoye posobiye dlya samostoyatel'noy podgotovki studentov vsekh form obucheniya. - M.: ID «Yurisprudentsiya», 2009. - 424 s.

5. Gadzhiyev G.A. Konstitutsionnyye printsipy dobrosovestnosti i nedopustimosti zloupotrebleniya sub"yektivnymi pravami // Gosudarstvo i pravo. - 2002. - № 7. S. 54-62.

6. Gulyayev A.P. Sledovatel' v ugolovnom protsesse. - M., 1981. - $192 \mathrm{~s}$

7. Darovskikh O.I. Aktual'nyye problemy ugolovnogo protsessa: uchebnoye posobiye. - Chelyabinsk: Izdatel'skiy tsentr YUUrGU, 2019. - CH.1. - $199 \mathrm{~s}$.

8. Yergashev Ye.R. Printsipy prokurorsko-nadzornogo prava i yego institutov: dis ... dokt. yurid. nauk. - Yekaterinburg, 2008. // Rezhim dostupa: https://www.dissercat. com/content/printsipy-prokurorskogo-nadzorno-okhranitelnogo-prava-i-egoinstitutov-0

9. Zazhitskiy V.I. Pravovyye printsipy v zakonodatel'stve Rossiyskoy Federatsii // Gosudarstvo i pravo. - 1996. - № 11. - S. 92-98.

10. Kashepov V.P. Gumanizatsiya ugolovnogo sudoproizvodstva kak printsip regulirovaniya rossiyskogo pravosudiya // Zhurnal rossiyskogo prava. - 2015. - № 12 . - S. 101-112. // Rezhim dostupa https://cyberleninka.ru/article/n/gumanizatsiyaugolovnogo-sudoproizvodstva-kak-printsip-regulirovaniya-rossiyskogo-pravosudiya 11. Kommentariy k Konstitutsii RF / pod red. B.N. Topornina, YU.M. Baturina, R.G. Orekhova. - M., 1994. - 623 s.

12. Malinovskiy A.A. Zloupotrebleniye pravom. - M., 2002. - $128 \mathrm{~s}$.

13. Malinovskiy A.A. Zloupotrebleniye sub"yektivnym pravom kak yuridicheskiy fenomen: dis. ... dokt. yurid. nauk. - M., 2003. - 404 s.

14. Murad'yan E.M. Sudebnoye pravo. - M., 2003. - $128 \mathrm{~s}$

15. Smirnov A.V., Kalinovskiy K.B. Ugolovnyy protsess. - SPb., 2004. - 704 s.

16. Strogovich M.S. Kurs sovetskogo ugolovnogo protsessa. - M., 1970. - T. 2. $616 \mathrm{~s}$

17. Tarasov A.A. Razvitiye sistemy printsipov ugolovnogo protsessa $v$ novom UPK Rossii // Ugolovno-protsessual'nyy kodeks Rossiyskoy Federatsii: god pravoprimeneniya i prepodavaniya. - M., 2004. - S. 71.

18. Yudin A.V. Zloupotrebleniye protsessual'nymi pravami v grazhdanskom sudoproizvodstve. - SPb.: Izdatel'skiy dom S.-Peterb. gos. un-ta, izdatel'stvo yuridicheskogo fakul'teta, 2005. - $360 \mathrm{~s}$

19. Yakimovich YU.K., Pan T.D. Sudebnoye proizvodstvo po UPK Rossiyskoy Federatsii. - SPb, 2005. - $264 \mathrm{~s}$

20. Yakub M.L. Demokraticheskiye osnovy sovetskogo ugolovno-protsessual'nogo prava. - M., 1960. - S. 135-138.

21. Arkhiv Kustanayskogo oblastnogo suda. Ugolovnoye delo № 3998-19-00-1/73. 22. Opredeleniye Moskovskogo oblastnogo suda ot 31 yanvarya 2012 goda № 332405/12.

ДАРОВСКИХ Ольга Игоревна, доцент кафедры уголовного процесса, криминалистики и судебной экспертизы ФГАОУ ВО «Южно-Уральский государственный университет» (НИУ), кандидат юридических наук, доцент. 454091, г. Челябинск, ул. Коммуны, д.149. E-mail: darovskikhoi@gmail.com.

DAROVSKIKH OIga Igorevna, Associate Professor of the Department of Criminal Procedure, Forensic Science and Forensic Expertise, South Ural State University (NRU), Candidate of Legal Sciences, Associate Professor. 454091, Chelyabinsk, st. Commune, 149. E-mail: darovskikhoi@gmail.com. 